\title{
New advances in the treatment of generalized lipodystrophy: role of metreleptin
}

This article was published in the following Dove Press journal:

Therapeutics and Clinical Risk Management

16 September 2015

Number of times this article has been viewed

\author{
Alexander J Rodriguez' \\ Claudio A Mastronardi² \\ Gilberto J Paz-Filho \\ 'Department of Medicine, Monash \\ Medical Centre, Clayton, VIC, \\ 2Department of Genome Sciences, \\ The John Curtin School of Medical \\ Research, The Australian National \\ University, Canberra, ACT, Australia
}

Video abstract

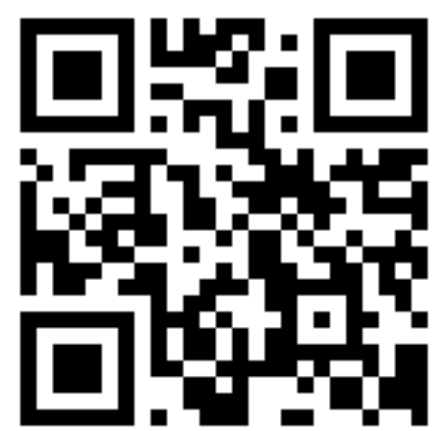

Point your SmartPhone at the code above. If you have a QR code reader the video abstract will appear. Or use: http://youtu.be/iat8NimLvXM

Correspondence: Gilberto J Paz-Filho Department of Genome Sciences, The John Curtin School of Medical Research, The Australian National University, 131 Garran Road, Acton,

ACT 260I, Australia

Tel +61262152380

Fax +6I 262156362

Email gilberto.pazfilho@anu.edu.au
Abstract: Recombinant methionyl human leptin or metreleptin is a synthetic leptin analog that has been trialed in patients with leptin-deficient conditions, such as leptin deficiency due to mutations in the leptin gene, hypothalamic amenorrhea, and lipodystrophy syndromes. These syndromes are characterized by partial or complete absence of adipose tissue and hormones derived from adipose tissue, most importantly leptin. Patients deficient in leptin exhibit a number of severe metabolic abnormalities such as hyperglycemia, hypertriglyceridemia, and hepatic steatosis, which can progress to diabetes mellitus, acute pancreatitis, and hepatic cirrhosis, respectively. For the management of these abnormalities, multiple therapies are usually required, and advanced stages may be progressively difficult to treat. Following many successful trials, the US Food and Drug Administration approved metreleptin for the treatment of nonHIV-related forms of generalized lipodystrophy. Leptin replacement therapy with metreleptin has, in many cases, reversed these metabolic complications, with improvements in glucoseinsulin-lipid homeostasis, and regression of fatty liver disease. Besides being effective, a daily subcutaneous administration of metreleptin is generally safe, but the causal association between metreleptin and immune complications (such as lymphoma) is still unclear. Moreover, further investigation is needed to elucidate mechanisms by which metreleptin leads to the development of anti-leptin antibodies. Herein, we review clinical aspects of generalized lipodystrophy and the pharmacological profile of metreleptin. Further, we examine studies that assessed the safety and efficacy of metreleptin, and outline some clinical perspectives on the drug.

Keywords: metreleptin, leptin, lipodystrophy, pharmacology, adipose tissue

\section{Introduction}

Lipodystrophy syndromes (LS) are a cluster of congenital and acquired conditions where adipose tissue is partially or fully absent. In those disorders, the subcutaneous adipose tissue is the most affected and fat accumulates in nonadipose tissues. In addition to cosmetic abnormalities, several metabolic defects may arise, such as insulin resistance, diabetes, and hypertriglyceridemia. These metabolic abnormalities can lead to the development of atherosclerosis, acute pancreatitis, and may evolve into the more serious nonalcoholic fatty liver disease (NAFLD) and cirrhosis. As LS comprise a heterogeneous group of disorders (congenital and acquired; partial and generalized), several other manifestations can occur, such as autoimmune or proteinuric kidney diseases. ${ }^{1-3}$

The pathogenesis of congenital forms of lipodystrophy is determined by molecular deficiencies in several genes that orchestrate adipocyte differentiation, lipid droplet morphology, and lipid metabolism. ${ }^{4-6}$ Acquired lipodystrophy may develop from the use of highly active retroviral therapy (HAART) or underlying HIV infection (the most common form of lipodystrophy) or autoimmune conditions. Generalized lipodystrophy 
is the most striking form of lipodystrophy and can be either acquired or congenital. ${ }^{7}$

The clinical manifestations of LS are essentially determined by the partial or complete lack of white adipose tissue, leading to low or undetectable levels of the adipose-derived cytokine leptin. ${ }^{3,8}$ Leptin is an adipocytokine that regulates several metabolic processes including glucose homeostasis, insulin sensitivity, and fatty acid oxidation. ${ }^{9}$ The state of leptin deficiency seen in lipodystrophy leads to the development of several metabolic abnormalities and approximately $80 \%$ of the patients with lipodystrophy fulfill the diagnostic criteria for metabolic syndrome. ${ }^{10}$

Leptin replacement therapy (LRT) has been trialed in humans with leptin deficiency due to LS or mutations in the leptin gene, in women with hypothalamic amenorrhea, and in patients with conditions such as obesity, diabetes, and severe insulin resistance. ${ }^{11}$ The safety and efficacy of such treatment led to the approval by the US Food and Drug Administration (FDA) in 2014 of the leptin analog metreleptin (Myalept, Aegerion Pharmaceuticals, Inc., Cambridge, MA, USA) for the treatment of non-HIV-related forms of generalized lipodystrophy. ${ }^{12,13}$

LRT is effective at ameliorating the metabolic and hepatic complications seen in LS, as well as in decreasing ectopic fat deposition in the liver and skeletal muscle. In mice and in humans, leptin improves abnormalities of glucose and lipid metabolism, increases insulin sensitivity, reduces the risk of further progression into NAFLD, and restores gonadotropin secretion. ${ }^{14,15}$ Due to some risks related to the development of neutralizing antibodies and lymphoma, US prescribers must be certified by enrolling in and completing specific training. Although it has been shown that LRT can be safe and effective also in patients with partial forms of lipodystrophy, ${ }^{15,16}$ its use is currently approved only for cases of generalized non-HIV lipodystrophy.

In this study, we revise the clinical and pathophysiological aspects of generalized lipodystrophy and its complications, focusing on the consequences of leptin deficiency. The pharmacological aspects of metreleptin are described, and the new advances on the use of metreleptin for the treatment of LS are discussed.

\section{Congenital generalized lipodystrophy}

Congenital generalized lipodystrophy (CGL; also known as Berardinelli-Seip syndrome) is an inherited autosomal recessive disorder present at birth. Berardinelli-Seip syndrome has a prevalence of approximately 1 in 10 million
( $\sim 300$ known cases worldwide, with the highest frequency in Brazil) individuals. ${ }^{17,18}$ Several important mutations have been identified as responsible for causing the syndrome; mutations of AGPAT2 and BSCL2 are responsible for 95\% of reported cases of CGL (type 1 and type 2 CGL, respectively). Type 3 CGL is associated with mutations of $C A V 1$, and type 4 CGL with mutations of PTRF.

The AGPAT2 gene encodes the enzyme 1-acylglycerol-3phosphate O-acyltransferase 2, which converts lysophosphatidic acid to phosphatidic acid (an important step in the de novo synthesis of phospholipids and triglycerides [TG]). ${ }^{19}$ Mutations in AGPAT2 are associated with CGL1, which is the most frequent form of CGL. The BSCL2 gene encodes the protein seipin, which is critical for normal adipogenesis. As it is located in the endoplasmic reticulum, sepin may also have a role in protein folding. ${ }^{20}$ CGL3, identified in only one patient to date, is caused by a mutation in $C A V 1$, a gene encoding caveolin 1 that binds and translocates fatty acids into lipid droplets. When the biological function of caveolin 1 is impaired, it disrupts insulin signaling and modulates GLUT4 function. ${ }^{21}$ CGL4 has been diagnosed in 21 patients and is associated with mutations in PTRF, a gene encoding cavin that participates in the biogenesis of caveolae and controls the expression of caveolins 1 and 3; loss of function of these caveolins also affects insulin signaling and modulates GLUT4 function. ${ }^{22}$ There are several other patients with CGL in whom no known mutations have been identified. Therefore, novel CGL genes may be identified in the future. ${ }^{23}$

The most striking clinical manifestations of CGL are abnormal appearance due to the absence of subcutaneous fat in the abdomen and thorax, which becomes evident within the first 2 years of life (but may be noticed at birth). In these patients, normal amounts of fat are present in the scalp, orbits, mouth, tongue, palms, soles, perineum, and periarticular regions. Children may present voracious appetite, accelerated linear growth, increased metabolic rate, and advanced bone age. Other abnormalities include acanthosis nigricans, protuberant abdomen due to hepatomegaly, cirrhosis, prominent musculature, precocious puberty, and mental retardation. ${ }^{2}$ In CGL2, due to seipin mutations, the pathology manifests as a more severe disease phenotype. Overall, in CGL, blood leptin concentrations are low, consistent with near total absence of body fat.

\section{Acquired generalized lipodystrophy}

The other main phenotype of generalized lipodystrophy is acquired generalized lipodystrophy (AGL, also known as Lawrence syndrome). This syndrome often appears in 
childhood and may develop over a number of weeks or years, and is often related to reactions to subcutaneous injections. To date, approximately 50 cases have been described. ${ }^{2}$ The prevalence statistics demonstrate that LS are rare but have serious conditions associated with them. Previous infection has been causally linked to AGL, as serological and histological examinations of the adipose tissue have revealed panniculitis and autoantibodies. ${ }^{24,25}$ The current understanding of the genetic basis for AGL is incomplete. ${ }^{23}$

Clinically, AGL can present in children as well as adults. Superficial veins and musculature become more prominent and hepatomegaly is a frequent presentation. Patients also frequently present with severe insulin resistance (and diabetes), hyperinsulinemia, hypertriglyceridemia, dyslipidemia (in particular low serum high-density lipoprotein [HDL]-cholesterol concentrations, high serum free fatty acids, and excessive lipolysis), and often a high metabolic rate. ${ }^{2}$ As previously mentioned, up to $80 \%$ of patients fulfill the criteria for metabolic syndrome. ${ }^{26}$ The metabolic profile of patients with LS is consistent with patients with a genetic leptin deficiency, and therefore leptin deficiency represents a specific therapeutic target for metabolic abnormalities in patients with lipodystrophy. Discussion about the synthetic leptin analog metreleptin and how it is used to treat the clinical manifestations in patients with CGL and AGL is detailed in the following section.

\section{Metreleptin}

Recombinant methionyl human leptin (r-met-HuLeptin) or simply metreleptin is a 146 amino acid $(\sim 16 \mathrm{kDa})$ protein that structurally is near-identical to the human leptin protein, except with the addition of a methionyl residue on the $\mathrm{N}$-terminal domain of the tertiary protein structure
(Table 1). ${ }^{11,12,27}$ Its action within the body mirrors that of the naturally occurring leptin hormone. However, the additional methionyl residue increases its half-life to approximately 3.8-4.7 hours, whereas previous studies have suggested that the half-life of a slower acting pool of leptin was 71 minutes. ${ }^{28}$ Metreleptin is administered as a once or twice daily subcutaneous injection preferably at the same time each day, to mimic the natural leptin circadian cycle. The recommended starting dose is dependent on the body weight of the subject, where for a body weight $\leq 40 \mathrm{~kg}$, the maximum daily dose is $0.13 \mathrm{mg} / \mathrm{kg}$; in people with a body weight $\geq 40 \mathrm{~kg}$, the maximum daily dose is $10 \mathrm{mg} /$ day. ${ }^{29}$ Pharmacological data have indicated that renal clearance is the main route of elimination, with no apparent contribution of systemic metabolism or degradation. Anti-leptin antibodies are known to develop, and this is expected to delay the clearance of metreleptin. Consequently, its biological effects are attenuated or completely neutralized. ${ }^{29}$ The most commonly reported adverse reactions associated with metreleptin use $(>10 \%)$ include headaches, hypoglycemia, abdominal pain, and weight loss. T-cell lymphoma has been reported in patients, but no causal relationship has been established. Also, autoimmune disorder progression has been observed in patients with autoimmune hepatitis and membranoproliferative glomerulonephritis. Hypersensitivity reactions such as generalized rash or urticaria have also been reported. Overall, the drug is well tolerated according to the various trials undertaken.

The contraindications for metreleptin include common obesity, which is not a result of genetic leptin deficiency (ie, leptin-resistant obesity) and hypersensitivity to drug treatment. As yet, there have been no studies of metreleptin in pregnant women; therefore, in these cases, metreleptin

Table I Pharmacological profile of metreleptin

\begin{tabular}{|c|c|}
\hline Pharmacological characteristics & Description \\
\hline Class & Adipose tissue-derived cytokine (adipocytokine/adipokine) recombinant analog \\
\hline Injection route & Subcutaneous \\
\hline Frequency & Once/twice daily (depending on dosing regimen) \\
\hline Starting dose & 0.06 mg/kg/day (in persons < 40 kg); 2.5 mg/day (males); 5.0 mg/day (females) \\
\hline Peak serum concentration (Cmax) & $4.0-4.3$ hours \\
\hline Time at peak serum concentration (Tmax) & 4 hours (range: $2-8$ ) \\
\hline Volume of distribution & 4-5 times plasma volume \\
\hline Clearance & Renal, decreased clearance in obesity and females; increased clearance with fasting \\
\hline Half-life & $3.8-4.7$ hours \\
\hline Adverse reactions & Headache, hypoglycemia, weight loss, fatigue, injection site reactions, abdominal pain \\
\hline Contraindications & Leptin-resistant obesity; hypersensitivity to metreleptin \\
\hline Known interactions & Potential to alter CYP450 enzyme formation \\
\hline Other & $\begin{array}{l}\text { Uncertain safety profile during pregnancy (no known studies); unknown optimal dosing } \\
\text { regimen for geriatric use }\end{array}$ \\
\hline
\end{tabular}

Note: Reprinted from Metabolism, 64 (I), Paz-Filho G, Mastronardi CA, Licinio J. Leptin treatment: facts and expectations, I46-I56. Copyright @ 20I5, with permission from Elsevier." 
Table 2 Documented effects of leptin in the body

\begin{tabular}{lll}
\hline Effects & Increase & Decrease \\
\hline $\begin{array}{l}\text { Physiological and anatomical } \\
\text { Metabolic }\end{array}$ & Satiety, physical activity & Body weight, fat mass, food intake, appetite \\
Endocrine & HDL-cholesterol, insulin sensitivity & Plasma glucose and insulin, liver fat and transaminases, triglycerides \\
& 24-hour cortisol, IGFBPI, IGFBP2 & Reversal of hypogonadism \\
Immunological & WBC, CD4+ T-cells, switch to Thl cytokine profile & \\
Neuroradiological & Activation of brain areas related to satiety and & Activation of brain areas related to hunger \\
& posterior lobe of cerebellum & \\
& Increase in regional gray matter concentration & \\
\hline
\end{tabular}

Note: Reprinted from Metabolism, 64 (I), Paz-Filho G, Mastronardi CA, Licinio J. Leptin treatment: facts and expectations, I46-I56. Copyright @ 20I5, with permission from Elsevier." Abbreviations: HDL, high-density lipoprotein; WBC, white blood cells; ThI, type I T helper cells.

treatment is not recommended, as there is no risk and safety data available to guide therapy. There have been no clinically significant differences in responses between pediatric or adult subjects, though careful adjustment of dosing regime is required in adolescent subjects, as they age and increase in body size and weight. Further, there is no definitive information of the effect of metreleptin in geriatric subjects. However, as liver and renal functions decline with advancing age, similar dose selection precautions need to be taken, and it is preferable to start treatment at the lower end of the dosing range. No formal drug interaction studies have been performed to elucidate the impact of metreleptin on cytochrome P450 (CYP450) enzyme. Since leptin is a cytokine with the potential to alter CYP450 expression, ${ }^{30}$ caution is warranted when prescribing metreleptin if the patient is simultaneously receiving drugs metabolized by CYP450, or if they are receiving metreleptin and are about to start a course of drugs metabolized by CYP450 with a narrow therapeutic index, such as oral contraceptives. ${ }^{27}$

At the molecular level, metreleptin shares structural homology to interleukin-6 (IL-6), IL-11, IL-12, and oncostatin $\mathrm{M}$, which are all members of the long-chain helical cytokine family. ${ }^{9}$ It binds to the leptin-receptor (OB-R) long isoform, which is expressed in many circulating and tissue-resident cells. These include a number of immune cells such as dendritic cells, macrophages, neutrophils, monocytes, subpopulations of T-and B-cells, mast cells, and natural killer cells. The receptor is also present in skeletal muscle and, most importantly, in the arcuate nucleus of the hypothalamus in the central nervous system. It is in this location that leptin exerts its powerful satiety effects. The long isoform is the only form of the leptin receptor that is capable of producing signal transduction via activation of the JAK/STAT pathway. ${ }^{9}$ Signal transduction takes place by activation of conserved box 1 and box 2 motifs (intracellular amino acids 6, 17 and 49-60, respectively), whereas the main binding site for leptin on the OB-R is cytokine receptor homology module 2 ( $\mathrm{CRH} 2)$. The fibronectin III
(FNIII) and the immunoglobulin-like (Ig-like) domains are largely involved in OB-R activation. With regards to the role of CRH1, it remains to be determined. ${ }^{9}$

At the physiological level, due to the broad expression of the OB-R, metreleptin has equally diverse effects in a number of systems. ${ }^{28}$ These effects are summarized in Table 2; the most important effects of metreleptin in relation to lipodystrophy are that metreleptin (like leptin) can decrease hunger and overall food intake. ${ }^{31}$ Further, metreleptin increases insulin sensitivity, enhancing glucose disposal in skeletal muscle and resulting in decreased plasma glucose. Leptin also reduces serum TG and steatosis, increases HDL cholesterol, and reduces plasma insulin. Additionally, metreleptin has the capacity to regulate a number of endocrine systems such as the somatotropic, corticotropic, gonadotropic, and thyrotropic axes, and also affects osteogenesis, angiogenesis, hematopoiesis, and wound healing. 3,27,32

\section{Trials of metreleptin in LS}

For over 15 years, LRT has been evaluated for safety and efficacy in patients with congenital leptin deficiency due to mutations in the leptin gene. In a cohort of morbidly obese patients of Turkish, Pakistani, and Austrian background, LRT has led to remarkable weight loss, normalization of the endocrine axes, and improvement of several physiological outcomes such as immune function, insulin sensitivity, lipid profile, and hepatic steatosis (Figure 1). ${ }^{11}$

There has been increasing interest in evaluating the effects of exogenous leptin on various conditions including lipodystrophy, HAART-induced lipodystrophy, common obesity, hypothalamic amenorrhea, type 1 and type 2 diabetes mellitus, NAFLD, and severe insulin resistance. The first successful report of metreleptin to treat lipodystrophy was produced by Oral et al in 2002. ${ }^{33}$ In their case series/ prospective study, nine female patients with low leptin levels associated with lipodystrophy (17-42 years old, eight diabetics receiving insulin and four patients receiving lipidlowering therapy) received daily subcutaneous injections of 

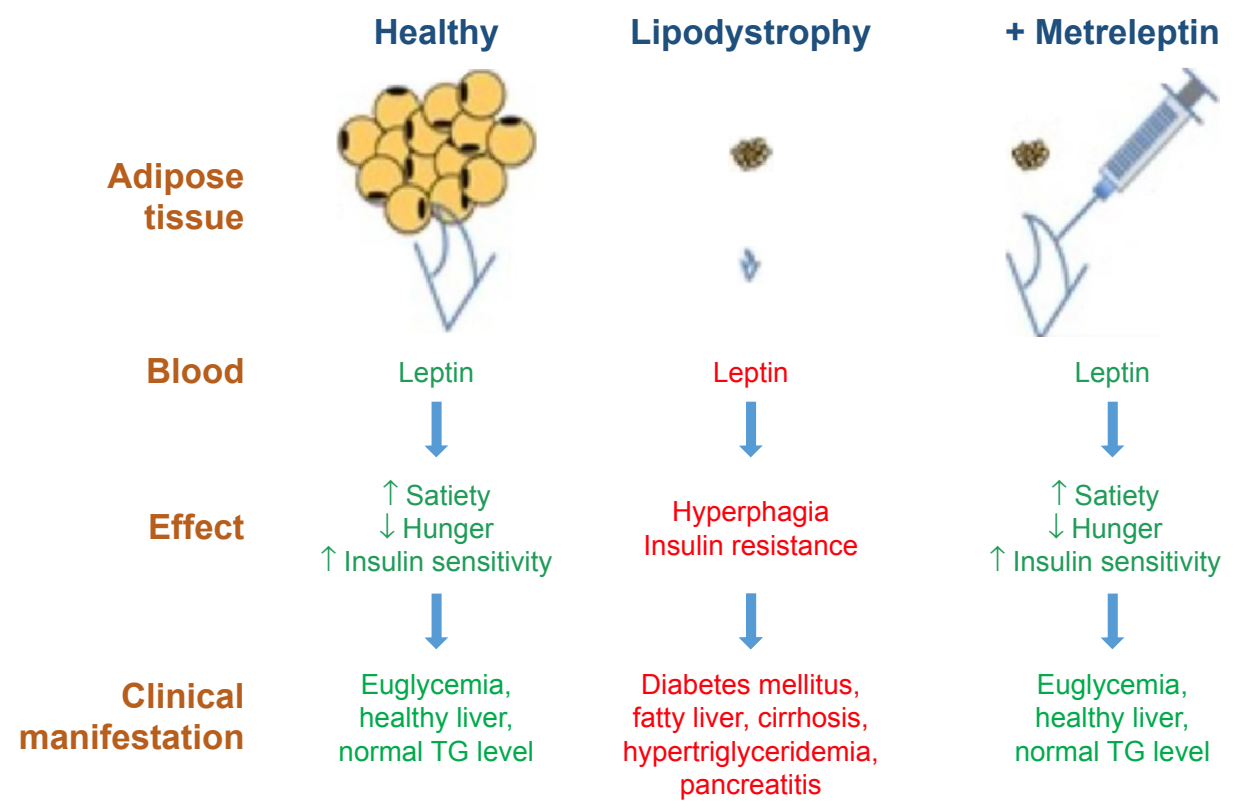

Figure I Clinical action of metreleptin treatment in adipose-deficient lipodystrophic patients. Abbreviation: TG, triglycerides.

metreleptin, and had their metabolic profile assessed at 1,2, 3 , and 4 months postinitiation of recombinant therapy. During treatment, the serum leptin level increased from a mean of $1.3 \pm 0.3 \mathrm{ng} / \mathrm{mL}$ to $11.1 \pm 2.5 \mathrm{ng} / \mathrm{mL}$ (equivalent to $0.1 \pm 0.02$ to $0.9 \pm 0.2 \mathrm{nmol} / \mathrm{mL}$ ). The absolute decrease in glycated hemoglobin $\left(\mathrm{HbA}_{1 \mathrm{c}}\right)$ value was $1.9 \%$ (where the $95 \%$ confidence interval $[\mathrm{CI}]$ ranged from $1.1 \%$ to $2.7 \% ; P=0.001$ ) in the eight diabetic patients. At 4-month follow-up, mean decrease in TG level was $60 \%$ (95\% CI: 43\%-77\%; $P<0.001)$. Liver volume decreased by a mean of $28 \%$ (95\% CI: $20 \%-36 \%$; $P=0.002)$ in all nine patients, and this was noted as leading to the discontinuation of, or a large reduction in, antidiabetic medication. Finally, self-reported daily caloric intake and the measured resting metabolic rate (which is high in LS patients) also decreased significantly with therapy. Overall, metreleptin was well tolerated in these patients. Followed by this seminal study, several other studies described the effects of LRT in patients with all forms of LS.

The announcement of approval by the FDA was coupled with the release of a briefing document prepared by BristolMyers Squibb and AstraZeneca for the Endocrine Society Metabolic Advisory Committee on Metreleptin into the integrated findings of NIH Study 991265, NIH Study 20010769, and FHA101. ${ }^{29}$ These studies were designed to assess the safety and efficacy of metreleptin, and specifically with the view to generate an evidence based on the effects of metreleptin on lipodystrophy. The studies also sought to evaluate several clinical outcomes inadequately controlled on traditional therapy such as hypertriglyceridemia and/or diabetes mellitus, and/or evidence of hepatic steatosis. The primary outcomes were the achievement of normal physiological levels of $\mathrm{HbA1c}$, fasting plasma glucose, TG, liver volume, and transaminases. Data were obtained from a combined cohort of 72 subjects. For patients weighing $\leq 40 \mathrm{~kg}$, leptin was administered at a starting low dose of $0.02 \mathrm{mg} /$ $\mathrm{kg}$, whereas for patients weighing $>40 \mathrm{~kg}$, leptin was administered at a higher dose of $1.25-2.5 \mathrm{mg} /$ day. ${ }^{29}$ All of these outcome parameters were largely improved following a 12-month trial period (Table 3 ).

It was noted that metreleptin led to more pronounced changes from baseline in patients with a more severe metabolic phenotype at baseline. This was shown in a subanalysis where the cohort outcomes were stratified according to the degree of elevation (above the normal range) of baseline metabolic parameters (Table 4). For instance, patients with generalized lipodystrophy displaying a baseline $\mathrm{HbA}_{1 \mathrm{c}} \geq 8 \%$ achieved a mean reduction of $2.7 \%$, whereas patients with a baseline $\mathrm{HbA}_{1 \mathrm{c}} \geq 6 \%$ displayed a significantly lower reduction of $2.3 \%$. Likewise, patients with partial lipodystrophy showing a baseline $\mathrm{HbA}_{1 \mathrm{c}} \geq 8 \%$ underwent a mean reduction of $1.4 \%$, whereas patients displaying baseline $\mathrm{HbA}_{1 \mathrm{c}} \geq 6 \%$ displayed a smaller mean reduction of $0.8 \%$. A comparable pattern of results was detected in all the parameters assessed, which suggests that in restoring a healthy phenotype, the effect of metreleptin was more pronounced in those patients with more severe underlying metabolic abnormalities. ${ }^{29}$

Furthermore, the results suggested that the efficacy of metreleptin was also more related to the underlying metabolic 
Table 3 Comparison of primary study end points from $\mathrm{NIH}$ lipodystrophy trials in patients with generalized and partial LS

\begin{tabular}{|c|c|c|c|}
\hline Parameter & $\mathbf{n}$ & Baseline & $\begin{array}{l}\text { Change after } \\
\text { metreleptin }\end{array}$ \\
\hline \multicolumn{4}{|l|}{$\mathrm{ALT}(\mathrm{U} / \mathrm{L})^{*}$} \\
\hline Combined & 52 & $\mathrm{n} / \mathrm{r}$ & $\mathrm{n} / \mathrm{r}$ \\
\hline Generalized LS & 31 & I30.4 (26.5) & $52.8(25.5)$ \\
\hline Partial LS & 21 & $58.4(13.8)$ & $0.3(6.3)$ \\
\hline \multicolumn{4}{|l|}{ AST (U/L)* } \\
\hline Combined & 51 & $\mathrm{n} / \mathrm{r}$ & $n / r$ \\
\hline Generalized LS & 30 & $94.1(17)$ & $35.7(2 \mid .2)$ \\
\hline Partial LS & 21 & $42.1(8.6)$ & $6.6(4.3)$ \\
\hline \multicolumn{4}{|l|}{$\mathrm{HbA}_{\mathrm{Ic}}(\%)^{*}$} \\
\hline Combined & 50 & $8.2(0.3)$ & I. $4(0.2)$ \\
\hline Generalized LS & 29 & $8.7(0.4)$ & $2.0(0.3)$ \\
\hline Partial LS & 21 & $7.5(0.5)$ & $0.4(0.2)$ \\
\hline \multicolumn{4}{|l|}{ FPG $(\mathrm{mg} / \mathrm{dL})^{*}$} \\
\hline Combined & 50 & $\mathrm{n} / \mathrm{r}$ & $n / r$ \\
\hline Generalized LS & 31 & I79.5 (I5.9) & $48.3(16.9)$ \\
\hline Partial LS & 21 & I55.8 (19.3) & $32.1(14.8)$ \\
\hline \multicolumn{4}{|l|}{$\mathrm{TG}(\mathrm{mg} / \mathrm{dL})^{\wedge}$} \\
\hline Combined & 51 & 359.0 & 121.0 \\
\hline Generalized LS & 30 & $4 \mid 4.5$ & 246.5 \\
\hline Partial LS & 21 & 357.0 & 74.0 \\
\hline
\end{tabular}

Notes: Adapted with permission Copyright @ $\odot$ 2014. Rodríguez AJ, Mastronardi CA, Paz-Filho G. Clinical perspectives: leptin replacement therapy for the treatment of lipodystrophy-associated non-alcoholic fatty liver disease. Transl Gastrointest Cancer. 20।4;4(I):98-107.62 *Data reported as mean (SE); ^data reported as median.

Abbreviations: LS, lipodystrophy syndromes; ALT, alanine transaminase; AST, aspartate aminotransferase; $\mathrm{HbA}_{\mathrm{lc}}$, glycated hemoglobin; FPG, fasting plasma glucose; TG, triglycerides; SE, standard error of the mean; $\mathrm{n} / \mathrm{r}$, not reported.

Table 4 Comparison of outcome in generalized and partial lipodystrophy patients with severe baseline metabolic abnormalities

\begin{tabular}{|c|c|c|c|c|}
\hline Parameter & $\begin{array}{l}\text { Lipodystrophy } \\
\text { subtype }\end{array}$ & $\mathbf{n}$ & Baseline & $\begin{array}{l}\text { Change after } \\
\text { metreleptin }\end{array}$ \\
\hline \multirow[t]{2}{*}{$A L T \geq 4 \mathrm{I} U / \mathrm{L}^{*}$} & Generalized & 31 & 171.6 & $72.0(35.2)$ \\
\hline & Partial & 8 & II $4.3(26.6)$ & $2.3(17.0)$ \\
\hline \multirow[t]{2}{*}{$\mathrm{AST} \geq 34 \mathrm{U} / \mathrm{L}^{*}$} & Generalized & 20 & $127.8(22.0)$ & $51.8(31.5)$ \\
\hline & Partial & 7 & $81.3(18.6)$ & $14.9(12.6)$ \\
\hline \multirow[t]{2}{*}{$\mathrm{HbA}_{\mathrm{Ic}} \geq 6 \% *$} & Generalized & 26 & $9.1(0.3)$ & $2.3(0.3)$ \\
\hline & Partial & 14 & $8.6(0.5)$ & $0.8(0.3)$ \\
\hline \multirow[t]{2}{*}{$\mathrm{HbA}_{\mathrm{Ic}} \geq 7 \% *$} & Generalized & 24 & $9.3(0.3)$ & $2.4(0.3)$ \\
\hline & Partial & 11 & $9.2(0.5)$ & $1.0(0.4)$ \\
\hline \multirow[t]{2}{*}{$\mathrm{HbA}_{\mathrm{Ic}} \geq 8 \% *$} & Generalized & 19 & $9.8(0.3)$ & $2.7(0.3)$ \\
\hline & Partial & 7 & I0.I (0.6) & $\mathrm{I} .4(0.4)$ \\
\hline \multirow[t]{2}{*}{$\mathrm{FPG} \geq 126 \mathrm{mg} / \mathrm{dL}^{*}$} & Generalized & 21 & $218.6(17.8)$ & $82.1(16.5)$ \\
\hline & Partial & 11 & $220.9(22.5)$ & $68.6(23.2)$ \\
\hline \multirow[t]{2}{*}{$\mathrm{TG} \geq 200 \mathrm{mg} / \mathrm{dL}^{\wedge}$} & Generalized & 21 & 600.0 & 432.0 \\
\hline & Partial & 16 & 430.0 & 95.5 \\
\hline \multirow[t]{2}{*}{$\mathrm{TG} \geq 500 \mathrm{mg} / \mathrm{dL}^{\wedge}$} & Generalized & 12 & I,526.5 & $1,117.0$ \\
\hline & Partial & 7 & $1,237.0$ & 499.0 \\
\hline
\end{tabular}

Notes: Adapted with permission Copyright @ 2 2014. Rodríguez AJ, Mastronardi CA, Paz-Filho G. Clinical perspectives: leptin replacement therapy for the treatment of lipodystrophy-associated non-alcoholic fatty liver disease. Transl Gastrointest Cancer. 2014;4(I):98-107.62 *Data reported as mean (SE); ^data reported as median.

Abbreviations: ALT, alanine transaminase; AST, aspartate aminotransferase; $\mathrm{HbA}$ glycated hemoglobin; FPG, fasting plasma glucose; TG, triglycerides; SE, standard error of the mean. dysfunction than to the form of lipodystrophy (generalized or partial). To assess this claim, a further subanalysis was performed whereby the data relating to $\mathrm{TG}$ and $\mathrm{HbA}_{1 \mathrm{c}}$ were stratified according to lipodystrophy subtype. As predicted, subanalysis results showed that more pronounced reductions in TG and $\mathrm{HbA}_{1 \mathrm{c}}$ were observed in patients with the generalized form, and comparable outcomes were observed in patients with variants of each lipodystrophy subtype (congenital or acquired). Overall, this suggested that metreleptin was more effective in improving the condition of patients with the generalized form of lipodystrophy, even though there is also emerging evidence suggesting that the efficacy of metreleptin could be independent of lipodystrophy etiology. ${ }^{15,16,29}$ Since patients with generalized lipodystrophy suffer more substantial mortality and morbidity due to complications arising from a number of severe metabolic abnormalities, ${ }^{34,35}$ it is easier to ascertain and/or predict the beneficial outcome of metreleptin therapy in patients with generalized lipodystrophy, as opposed to patients with partial lipodystrophy. Furthermore, as patients with partial lipodystrophy showed a more heterogeneous disease profile, there was an increased variability in the severity of their metabolic abnormalities. However, a recent study contradicts this notion where metreleptin was shown to produce equivalent improvements in patients with partial lipodystrophy. ${ }^{16}$ In this study, response to treatment was most likely in patients with partial lipodystrophy with $\mathrm{TG}>500 \mathrm{mg} / \mathrm{dL}$ at baseline or $\mathrm{HbA}_{1 \mathrm{c}}>8 \%$. There were also significant improvements in $\mathrm{HbA}_{1 \mathrm{c}}$ and $\mathrm{TG}$ in partial lipodystrophy patients with endogenous leptin less than $4 \mathrm{ng} / \mathrm{mL}$ (which is comparable with leptin levels seen in cases of generalized lipodystrophy), regardless of the severity of their lipid or glucose abnormalities. Further, there were some patients who did not fulfill these criteria, who nonetheless showed metabolic improvement in response to metreleptin treatment. Collectively, these data largely suggest that exogenous administration of leptin can return key liver parameters and biochemical markers to normal ranges in patients with lipodystrophy.

Metreleptin represents the first comprehensive treatment regime for lipodystrophy, as previously patients were required to receive multiple medications to treat lipodystrophy complications (insulin resistance and fatty liver disease). Currently, there are no studies yet comparing the effects of metreleptin versus conventional treatment of lipodystrophy complications, especially considering that metreleptin is still in its infancy as a stand-alone treatment. However, there are a number of studies evaluating the effects of metreleptin in heterogeneous groups of lipodystrophic patients, examining a number of different outcomes which we have previously reviewed. ${ }^{15}$ Our meta-analysis sought data relating to 16 
glycemic, hepatic, and lipid outcomes in 226 patients from 12 studies. ${ }^{26,36-47}$ Of these outcomes, metreleptin produced improvements (measured as reductions in standardized mean difference units [SMD] compared to a baseline measurement) in fasting glucose (0.75 SMD [range 0.36-1.13], $P=0.0001), \mathrm{HbA}_{1 \mathrm{c}}(0.49 \mathrm{SMD}[0.17-0.81], P=0.003)$, TG SMD (1.00 [0.69-1.31], $P<0.00001)$, total cholesterol (0.62 SMD [0.21-1.02], $P=0.003)$, liver volume (1.06 SMD [0.51-1.61], $P=0.0002)$, and aspartate aminotransferase $(0.41$ $\operatorname{SMD}[0.10-0.73] P=0.01)$. Despite this, some studies reported that in the short term, metreleptin did not significantly alter $\beta$-cell function or increase insulin. ${ }^{48}$ Other studies have also shown that metreleptin did not affect bone mineral content due to its effect on increasing lean mass. ${ }^{49}$

\section{Safety considerations of metreleptin}

Metreleptin has an overall favorable safety profile. In NIHsponsored trials, there were 308 events in total, of which 51 were treatment-emergent adverse events. ${ }^{29}$ Importantly, only three of these events comprised death, and only two participants discontinued treatment. The documented risks from treatment are lymphoma and the potential risk for loss of drug efficacy if anti-metreleptin antibodies develop. Further, nonresponsiveness has also been attributed to leptin resistance of an immunological origin. Other reported adverse events, with a greater than $5 \%$ frequency, were hypoglycemia, fatigue, nausea, weight loss, abdominal pain, alopecia, ovarian cyst, pain at extremity, and upper respiratory tract infection. Other less frequent $(<5 \%)$ adverse events include: arthralgia, constipation, diarrhea, ear infections, pancreatitis, renal cysts, urinary tract infection, vomiting, injection site hematoma, injection site urticaria, lymphadenopathy, sinusitis, muscle spasms, myalgia, and anxiety. ${ }^{29}$

Decision-making regarding metreleptin treatment for generalized lipodystrophy is more straightforward than partial lipodystrophy for a number of reasons. Principally, generalized lipodystrophy, whether congenital or acquired, is a condition associated with substantial morbidity and mortality arising from complications of several severe metabolic abnormalities. These abnormalities include hyperglycemia, hypertriglyceridemia, and altered liver transaminase profile. Additionally, these complications are often not responsive or suboptimally controlled on standard therapies (eg, metformin or statins). Subtypes of generalized lipodystrophy are typically diagnosed in childhood, which adds to their risk of developing severe morbidity and premature mortality. Metreleptin treatment in patients with generalized lipodystrophy has been demonstrated to improve the multiple metabolic abnormalities, and the magnitude of improvement correlates with the severity of the specific baseline metabolic abnormalities present. ${ }^{15}$

T-cell lymphoma has been noted in three out of 17 patients $(18 \%)$ in NIH trials, ${ }^{50}$ an incidence significantly higher than what is observed in the general population (approximately two per 100,000). However, evidence available from preclinical studies supports the conclusion that metreleptin is unlikely to cause T-cell lymphoma de novo. Rather, lymphoma can be more considered a feature of lipodystrophy instead of an effect of metreleptin treatment per se. ${ }^{51}$ The fact that lipodystrophy and lymphoma are known to coexist may be related to underlying autoimmunity, particularly for acquired forms, as these varieties are thought to arise out of autoimmune destruction of adipocytes despite the absence of positive autoimmune markers. ${ }^{25}$ Furthermore, it appears that patients with acquired lipodystrophy are at an increased risk of peripheral T-cell lymphoma, which is a heterogeneous and generally aggressive disorder. It is thought to be related to acquired lipodystrophy, as a subtype of peripheral T-cell lymphoma localizes to the subcutaneous fat, termed subcutaneous panniculitis-like T-cell lymphoma. This colocalization represents a pathophysiologic link between the development of AGL and T-cell lymphomas. ${ }^{52}$ The clinical assessment of the potential role of metreleptin in contributing to development and/or progression of lymphoma is limited by the lack of placebo controls. Thus, a potential role cannot be fully excluded.

Given the extensive loss of subcutaneous adipose tissue, and to the significant metabolic abnormalities attributed to this, patients with generalized lipodystrophy are at an extremely high risk of morbidity and mortality. Therefore, the potential for these patients to achieve benefits needs to be taken into consideration for this population. In other words, although the potential for the development of T-cell lymphoma represents a substantial risk, for most patients the numerous severe metabolic abnormalities and proven benefits of metreleptin use will likely outweigh concerns for development or progression of lymphoma. ${ }^{27}$

The development of anti-metreleptin antibodies is extremely frequent (reported in up to $95 \%$ of cases), but its consequences have not been well characterized. The primary concern regarding anti-metreleptin antibodies is the potential for neutralizing activity against endogenous leptin, which may eventually lead to a loss of efficacy of metreleptin therapy. In NIH-sponsored lipodystrophy trials, patients who developed anti-metreleptin antibodies had poorer glycemic control and increased susceptibility to infection or increased resolution time (some of which requiring hospitalization). ${ }^{29}$ No standardized guidelines have been developed in regards to a clinical response to anti-metreleptin antibodies, but regular 
assessment of anti-metreleptin titers are recommended in patients who develop frequent or persistent infections.

Unlike patients with generalized lipodystrophy, patients with partial lipodystrophy present a more heterogeneous phenotype, as the severity of the multiple morbidities varies between cases. This is typically the result of varying degrees of adipose tissue loss and the location of that loss. Therefore, in considering the appropriateness of metreleptin treatment, clinical diagnosis based on significant loss of adipose tissue in regional distribution patterns together with a thorough physical examination and evaluation of abnormalities (including hypertriglyceridemia, insulin-resistant diabetes mellitus, and/or hepatic steatosis or hepatomegaly) are important considerations in guiding a treatment decision. Consideration should also be given to the patient's responsiveness to conventional treatments for the multiple complications (eg, lipid-lowering and antidiabetic therapies). Metreleptin fulfills an important unmet need, which is providing a single therapy able to control metabolic abnormalities that are not effectively controlled through existing treatments.

Other complications inherent to lipodystrophy and that may exacerbate with metreleptin therapy include pancreatitis due to the hypertriglyceridemia (particularly when lipidlowering drugs are being tapered down) and membranoproliferative glomerulonephritis, which is a form of renal injury secondary to lipodystrophy that may aggravate with metreleptin therapy. Finally, immune-related hypersensitivity reactions include urticaria, anaphylaxis, papular rash, angioedema, pruritus, and injection site reactions. ${ }^{27}$

\section{Patient perspectives}

Given the recent approval by the FDA, further investigation into other clinical effects of metreleptin will likely be better supported, as further research is needed, specifically regarding further postmarket monitoring in generalized lipodystrophy and safety/efficacy in partial lipodystrophy. This is in order to richen the understanding of adverse events and of long-term tolerability and effectiveness, given that many instances of generalized lipodystrophy occur in childhood or adolescence. Other patient-focused perspectives will likely also become apparent, such as improvements in quality of life, adherence and uptake, and overall satisfaction and acceptability of treatment. Currently, there is a paucity of evidence on these important patient-oriented outcomes.

\section{Metreleptin in other conditions}

Safety and efficacy of metreleptin have also been evaluated in patients with other forms of leptin deficiency, ie, humans with leptin deficiency due to mutations in the leptin gene and women with hypothalamic amenorrhea, and in patients with normal or high leptin levels, such as diabetes, obesity, and severe insulin resistance. ${ }^{11}$ In those leptin-deficient patients, LRT leads to remarkable improvements or normalization of the gonadal, adrenal, thyroid, and somatotropic axes, and to the restoration to normal immune and metabolic parameters. Specifically in morbidly obese patients with mutations in the leptin gene, LRT leads to substantial weight loss (mean body mass index decrease of approximately 50\% in adults). ${ }^{11}$ In women with hypothalamic amenorrhea, LRT increases bone mineral density and content in the lumbar spine. ${ }^{53}$

In patients with common obesity and diabetes, LRT does not lead to such remarkable changes because these patients have normal or high leptin levels, and frequently have increased leptin resistance. ${ }^{54}$ The effects of LRT on body weight of obese patients are highly heterogeneous; some studies showed no effect, ${ }^{55}$ whereas others showed significant weight loss in a subset of patients with relatively low leptin levels, treated with higher doses. ${ }^{56,57}$ In Phase II clinical trials, others have shown that pramlintide (an analog to amylin, the hormone secreted by the pancreas leading to short-term satiety) has synergistic effect to metreleptin and increases the percentage of total weight loss to $12.7 \% .{ }^{58}$ However, further studies were suspended by the sponsors, based on commercial grounds and due to the development of anti-metreleptin antibodies in three out of 579 patients treated with metreleptin + pramlintide. It is still unclear whether obese patients are more likely than lipodystrophy patients to develop antibodies, and whether these antibodies are more likely to have neutralizing effect. In all of those three previously reported patients, anti-metreleptin antibodies had neutralizing activity leading to loss of the drug's effect, weight gain by more than $10 \mathrm{~kg}$, and significant decrease in fasting leptin levels, compared to baseline. ${ }^{59}$ Therefore, particularly in leptin-sufficient patients, neutralizing antibodies could catastrophically induce a leptin-deficient state.

Similarly, patients with type 2 diabetes are frequently overweight or obese and, consequently, hyperleptinemic with increased leptin resistance. Therefore, leptin therapy does not significantly affect body weight, body composition, glucose levels, insulin sensitivity, and HbA1c.57,60 There are no results available for trials assessing the effects of metreleptin in patients with type 1 diabetes.

\section{The future of metreleptin}

As a drug in clinical practice, metreleptin is still in its infancy. As longitudinal data emerges, better understanding of its 
safety and efficacy is becoming available, not only in the context of generalized lipodystrophy, but also of other disorders such as partial lipodystrophy, HIV-related lipodystrophy, congenital leptin deficiency due to mutations in the leptin gene, hypothalamic amenorrhea, common obesity, diabetes, and fatty liver disease. Furthermore, preclinical data suggest that metreleptin may also be useful for neurodegenerative diseases and psychiatric disorders. ${ }^{61}$

Currently, metreleptin potentially offers an avenue for physicians and patients to replace the need to have multiple medications to treat the metabolic consequences of adipose tissue deficiency. Metreleptin is safe and effective with very few examples of leptin resistance arising from treatment. If current and future clinical trials show that metreleptin is safe and effective for the treatment of other disorders, in addition to non-HIV-generalized lipodystrophy, new leptin-based therapies may become available to a broader population.

\section{Disclosure}

The authors report no conflicts of interest in this work.

\section{References}

1. Fiorenza CG, Chou SH, Mantzoros CS. Lipodystrophy: pathophysiology and advances in treatment. Nat Rev Endocrinol. 2011;7(3):137-150.

2. Garg A. Clinical review: lipodystrophies: genetic and acquired body fat disorders. J Clin Endocrinol Metab. 2011;96(11):3313-3325.

3. Tsoukas MA, Farr OM, Mantzoros CS. Leptin in congenital and HIVassociated lipodystrophy. Metabolism. 2015;64(1):47-59.

4. Cinti S, Frederich RC, Zingaretti MC, De Matteis R, Flier JS, Lowell BB. Immunohistochemical localization of leptin and uncoupling protein in white and brown adipose tissue. Endocrinology. 1997; 138(2):797-804.

5. Garg A, Kircher M, Del Campo M, Amato RS, Agarwal AK, University of Washington Center for Mendelian G. Whole exome sequencing identifies de novo heterozygous CAV1 mutations associated with a novel neonatal onset lipodystrophy syndrome. Am J Med Genet A. 2015; 167(8):1796-1806.

6. Vigouroux C, Caron-Debarle M, Le Dour C, Magre J, Capeau J. Molecular mechanisms of human lipodystrophies: from adipocyte lipid droplet to oxidative stress and lipotoxicity. Int J Biochem Cell Biol. 2011; 43(6):862-876.

7. Chan JL, Oral EA. Clinical classification and treatment of congenital and acquired lipodystrophy. Endocr Pract. 2010;16(2):310-323.

8. Cortes VA, Fernandez-Galilea M. Lipodystrophies: adipose tissue disorders with severe metabolic implications. J Physiol Biochem. Epub 2015 Apr 2.

9. Paz-Filho G, Mastronardi C, Franco CB, Wang KB, Wong ML, Licinio J. Leptin: molecular mechanisms, systemic pro-inflammatory effects, and clinical implications. Arq Bras Endocrinol Metabol. 2012; 56(9):597-607.

10. Gorden P, Lupsa BC, Chong AY, Lungu AO. Is there a human model for the 'metabolic syndrome' with a defined aetiology? Diabetologia. 2010;53(7):1534-1536.

11. Paz-Filho G, Mastronardi CA, Licinio J. Leptin treatment: facts and expectations. Metabolism. 2015;64(1):146-156.

12. Chou K, Perry CM. Metreleptin: first global approval. Drugs. 2013; 73(9):989-997.

13. Sinha G. Leptin therapy gains FDA approval. Nat Biotechnol. 2014; 32(4):300-302.
14. Paz-Filho G, Mastronardi CA, Parker BJ, et al. Molecular pathways involved in the improvement of non-alcoholic fatty liver disease. $\mathrm{J} \mathrm{Mol}$ Endocrinol. 2013;51(1):167-179.

15. Rodriguez AJ, Neeman T, Giles AG, Mastronardi CA, Paz Filho G. Leptin replacement therapy for the treatment of non-HAART associated lipodystrophy syndromes: a meta-analysis into the effects of leptin on metabolic and hepatic endpoints. Arq Bras Endocrinol Metabol. 2014;58(8):783-797.

16. Diker-Cohen T, Cochran E, Gorden P, Brown RJ. Partial and generalized lipodystrophy: comparison of baseline characteristics and response to metreleptin. J Clin Endocrinol Metab. 2015;100(5):1802-1810.

17. Agarwal AK, Garg A. Genetic basis of lipodystrophies and management of metabolic complications. Annu Rev Med. 2006;57:297-311.

18. Barra CB, Savoldelli RD, Manna TD, et al. Genetic and metabolic description of five patients with Berardinelli-Seip syndrome. Arq Bras Endocrinol Metabol. 2011;55(1):54-59.

19. Agarwal AK, Arioglu E, De Almeida S, et al. AGPAT2 is mutated in congenital generalized lipodystrophy linked to chromosome 9q34. Nat Genet. 2002;31(1):21-23.

20. Magre J, Delepine M, KhalloufE, et al. Identification of the gene altered in Berardinelli-Seip congenital lipodystrophy on chromosome 11q13. Nat Genet. 2001;28(4):365-370.

21. Kim CA, Delepine M, Boutet E, et al. Association of a homozygous nonsense caveolin-1 mutation with Berardinelli-Seip congenital lipodystrophy. J Clin Endocrinol Metab. 2008;93(4):1129-1134.

22. Hayashi YK, Matsuda C, Ogawa M, et al. Human PTRF mutations cause secondary deficiency of caveolins resulting in muscular dystrophy with generalized lipodystrophy. J Clin Invest. 2009;119(9):2623-2633.

23. Nolis T. Exploring the pathophysiology behind the more common genetic and acquired lipodystrophies. J Hum Genet. 2014;59(1):16-23.

24. Billings JK, Milgraum SS, Gupta AK, Headington JT, Rasmussen JE. Lipoatrophic panniculitis: a possible autoimmune inflammatory disease of fat. Report of three cases. Arch Dermatol. 1987;123(12): 1662-1666.

25. Hubler A, Abendroth K, Keiner T, et al. Dysregulation of insulin-like growth factors in a case of generalized acquired lipoatrophic diabetes mellitus (Lawrence Syndrome) connected with autoantibodies against adipocyte membranes. Exp Clin Endocrinol Diabetes. 1998;106(1):79-84.

26. Safar Zadeh E, Lungu AO, Cochran EK, et al. The liver diseases of lipodystrophy: the long-term effect of leptin treatment. J Hepatol. 2013; 59(1):131-137.

27. Tchang BG, Shukla AP, Aronne LJ. Metreleptin and generalized lipodystrophy and evolving therapeutic perspectives. Expert Opin Biol Ther. 2015; 15(7):1061-1075.

28. Hill RA, Margetic S, Pegg GG, Gazzola C. Leptin: its pharmacokinetics and tissue distribution. Int J Obes Relat Metab Disord. 1998;22(8):765-770.

29. Bristol-Myers Squibb Company. Endocrinologic and Metabolic Drugs Advisory Committee Briefing Document 2013; 2013. Available from: http://www.fda.gov/downloads/AdvisoryCommittees/CommitteesMeetingMaterials/Drugs/EndocrinologicandMetabolicDrugsAdvisoryCommittee/UCM377929.pdf. Accessed July 8, 2015

30. Watson AM, Poloyac SM, Howard G, Blouin RA. Effect of leptin on cytochrome P-450, conjugation, and antioxidant enzymes in the ob/ob mouse. Drug Metab Dispos. 1999;27(6):695-700.

31. Boguszewski CL, Paz-Filho G, Velloso LA. Neuroendocrine body weight regulation: integration between fat tissue, gastrointestinal tract, and the brain. Endokrynol Pol. 2010;61(2):194-206.

32. Paz-Filho G, Wong ML, Licinio J. Ten years of leptin replacement therapy. Obes Rev. 2011;12(5):e315-e323.

33. Oral EA, Simha V, Ruiz E, et al. Leptin-replacement therapy for lipodystrophy. N Engl J Med. 2002;346(8):570-578.

34. Daher E, Silva Junior G, Benevides V, et al. Berardinelli syndrome. A case report with fatal outcome. Invest Clin. 2008;49(2): 251-255.

35. Seip M, Trygstad O. Generalized lipodystrophy, congenital and acquired (lipoatrophy). Acta Paediatr Suppl. 1996;413:2-28. 
36. Beltrand J, Beregszaszi M, Chevenne D, et al. Metabolic correction induced by leptin replacement treatment in young children with Berardinelli-Seip congenital lipoatrophy. Pediatrics. 2007; 120(2):e291-e296.

37. Beltrand J, Lahlou N, Le Charpentier T, et al. Resistance to leptinreplacement therapy in Berardinelli-Seip congenital lipodystrophy: an immunological origin. Eur J Endocrinol. 2010;162(6):1083-1091.

38. Chan JL, Lutz K, Cochran E, et al. Clinical effects of long-term metreleptin treatment in patients with lipodystrophy. Endocr Pract. 2011; 17(6):922-932.

39. Chong AY, Lupsa BC, Cochran EK, Gorden P. Efficacy of leptin therapy in the different forms of human lipodystrophy. Diabetologia. 2010;53(1):27-35.

40. Ebihara K, Kusakabe T, Hirata M, et al. Efficacy and safety of leptinreplacement therapy and possible mechanisms of leptin actions in patients with generalized lipodystrophy. J Clin Endocrinol Metab. 2007; 92(2):532-541.

41. Javor ED, Cochran EK, Musso C, Young JR, Depaoli AM, Gorden P. Long-term efficacy of leptin replacement in patients with generalized lipodystrophy. Diabetes. 2005;54(7):1994-2002.

42. Javor ED, Ghany MG, Cochran EK, et al. Leptin reverses nonalcoholic steatohepatitis in patients with severe lipodystrophy. Hepatology. 2005;41(4):753-760.

43. Moran SA, Patten N, Young JR, et al. Changes in body composition in patients with severe lipodystrophy after leptin replacement therapy. Metabolism. 2004;53(4):513-519.

44. Oral EA, Ruiz E, Andewelt A, et al. Effect of leptin replacement on pituitary hormone regulation in patients with severe lipodystrophy. J Clin Endocrinol Metab. 2002;87(7):3110-3117.

45. Park JY, Javor ED, Cochran EK, DePaoli AM, Gorden P. Long-term efficacy of leptin replacement in patients with Dunnigan-type familial partial lipodystrophy. Metabolism. 2007;56(4):508-516.

46. Petersen KF, Oral EA, Dufour S, et al. Leptin reverses insulin resistance and hepatic steatosis in patients with severe lipodystrophy. J Clin Invest. 2002;109(10):1345-1350.

47. Simha V, Subramanyam L, Szczepaniak L, et al. Comparison of efficacy and safety of leptin replacement therapy in moderately and severely hypoleptinemic patients with familial partial lipodystrophy of the Dunnigan variety. J Clin Endocrinol Metab. 2012;97(3):785-792.

48. Muniyappa R, Brown RJ, Mari A, et al. Effects of leptin replacement therapy on pancreatic beta-cell function in patients with lipodystrophy. Diabetes Care. 2014;37(4):1101-1107.

49. Christensen JD, Lungu AO, Cochran E, et al. Bone mineral content in patients with congenital generalized lipodystrophy is unaffected by metreleptin replacement therapy. J Clin Endocrinol Metab. 2014;99(8):E1493-E1500.
50. Brown RJ, Chan JL, Jaffe ES, et al. Lymphoma in acquired generalized lipodystrophy. Leuk Lymphoma. Epub 2015 Feb 13.

51. Aslam A, Savage DB, Coulson IH. Acquired generalized lipodystrophy associated with peripheral T cell lymphoma with cutaneous infiltration. Int J Dermatol. 2015;54(7):827-829.

52. Yiannias JA, DiCaudo DJ, Maskin E. Peripheral T-cell lymphoma presenting as lipoatrophy and nodules. Int J Dermatol. 2006;45(12): 1415-1419.

53. Sienkiewicz E, Magkos F, Aronis KN, et al. Long-term metreleptin treatment increases bone mineral density and content at the lumbar spine of lean hypoleptinemic women. Metabolism. 2011;60(9):1211-1221.

54. Mark AL. Selective leptin resistance revisited. Am J Physiol Regul Integr Comp Physiol. 2013;305(6):R566-R581.

55. Zelissen PM, Stenlof K, Lean ME, et al. Effect of three treatment schedules of recombinant methionyl human leptin on body weight in obese adults: a randomized, placebo-controlled trial. Diabetes Obes Metab. 2005;7(6):755-761.

56. Heymsfield SB, Greenberg AS, Fujioka K, et al. Recombinant leptin for weight loss in obese and lean adults: a randomized, controlled, dose-escalation trial. J Am Med Assoc. 1999;282(16):1568-1575.

57. Moon HS, Matarese G, Brennan AM, et al. Efficacy of metreleptin in obese patients with type 2 diabetes: cellular and molecular pathways underlying leptin tolerance. Diabetes. 2011;60(6):1647-1656.

58. Ravussin E, Smith SR, Mitchell JA, et al. Enhanced weight loss with pramlintide/metreleptin: an integrated neurohormonal approach to obesity pharmacotherapy. Obesity (Silver Spring). 2009;17(9): 1736-1743.

59. Tam CS, Lecoultre V, Ravussin E. Novel strategy for the use of leptin for obesity therapy. Expert Opin Biol Ther. 2011;11(12):1677-1685.

60. Mittendorfer B, Horowitz JF, DePaoli AM, McCamish MA, Patterson BW, Klein S. Recombinant human leptin treatment does not improve insulin action in obese subjects with type 2 diabetes. Diabetes. 2011;60(5):1474-1477.

61. Farr OM, Tsoukas MA, Mantzoros CS. Leptin and the brain: influences on brain development, cognitive functioning and psychiatric disorders. Metabolism. 2015;64(1):114-130.

62. Rodríguez AJ, Mastronardi CA, Paz-Filho G. Clinical perspectives: leptin replacement therapy for the treatment of lipodystrophy-associated non-alcoholic fatty liver disease. Transl Gastrointest Cancer. 2014;4(1):98-107.
Therapeutics and Clinical Risk Management

\section{Publish your work in this journal}

Therapeutics and Clinical Risk Management is an international, peerreviewed journal of clinical therapeutics and risk management, focusing on concise rapid reporting of clinical studies in all therapeutic areas, outcomes, safety, and programs for the effective, safe, and sustained use of medicines. This journal is indexed on PubMed Central, CAS,

\section{Dovepress}

EMBase, Scopus and the Elsevier Bibliographic databases. The manuscript management system is completely online and includes a very quick and fair peer-review system, which is all easy to use. Visit http://www.dovepress.com/testimonials.php to read real quotes from published authors. 